\title{
Comunicación
}

\section{DETECCIÓN DE ILEITIS NECRÓTICA CAUSADA POR Lawsonia intracellularis EN PORCINOS DE GRANJAS TECNIFICADAS DE LA ZONA DE LIMA}

\author{
Sonia Calle E. ${ }^{1}$, Alfonso Chavera C. ${ }^{2}$, Nieves Sandoval Ch. ${ }^{2}$, Néstor Falcón P. ${ }^{3}$, \\ Marlon Torres A. ${ }^{4}$ y María Valdez C. $^{4}$
}

\section{AbStract}

The objective of the present study was to determine the presence of Lawsonia intracellularis in Peru. A total of 197 serum samples were evaluated by the immunofluorescence test. The seroprevalence was 38.7\% (73/197) and most of the affected animals were in the fattening stage. Eight percent of animals showed diarrhea and lost of body condition. Slaughtered animals showed various anatomical ileal damages. The histopathological lesions in ileon were compatible with necrotic ileitis caused by Lawsonia intracellularis. The Warthin Starry technique was used to confirm these results.

Key words: Lawsonia, ileitis, diarhea

La enteropatía proliferativa porcina o ileitis es causada por Lawsonia intracellularis. Esta bacteria es de distribución mundial y se presenta con mayor frecuencia en granjas porcinas de alto nivel sanitario. Requiere la presencia de otras bacterias de la flora digestiva para iniciar la colonización a nivel de los enterocitos, siendo la transmisión más frecuente por vía oral, donde el periodo de incubación es de 2 a 3 semanas.

El estudio de esta bacteria se inició en 1993 (Gebhart et al .,1993), pero las lesiones se conocen desde tiempo atrás (Biester y Schwarte, 1931). En 1995 se llegó a definir como el agente causal de la ileitis de la bacteria L. intracellularis, logrando su aislamien- to a partir de cultivos celulares en enterocitos de rata (McOrist et al., 1995, 1997). Se ha reportado en los Estados Unidos de Norte América y en algunos países de Europa (Pointon, 1989). Estudios realizados en Brasil (Chiriboga et al., 1999) y Venezuela (Hurtado et al., 1999) indican frecuencias cercanas al $34 \%$ de animales positivos, lo que demuestra la difusión de la enfermedad en la región.

La enfermedad provoca una disfunción intestinal grave que en ocasiones puede causar la muerte de los animales. En casos más leves, cursa con apatía, anorexia y retraso en el crecimiento, complicándose en los casos crónicos con épocas alternas de diarrea

\footnotetext{
${ }^{1}$ Laboratorio de Microbiología y Parasitología Veterinaria, FMV-UNMSM.E-mail: calleson@ gmail.com

${ }^{2}$ Laboratorio de Histología, Embriología y Patología Veterinaria, FMV-UNMSM

${ }^{3}$ Laboratorio de Medicina Veterinaria Preventiva, FMV-UNMSM
} 


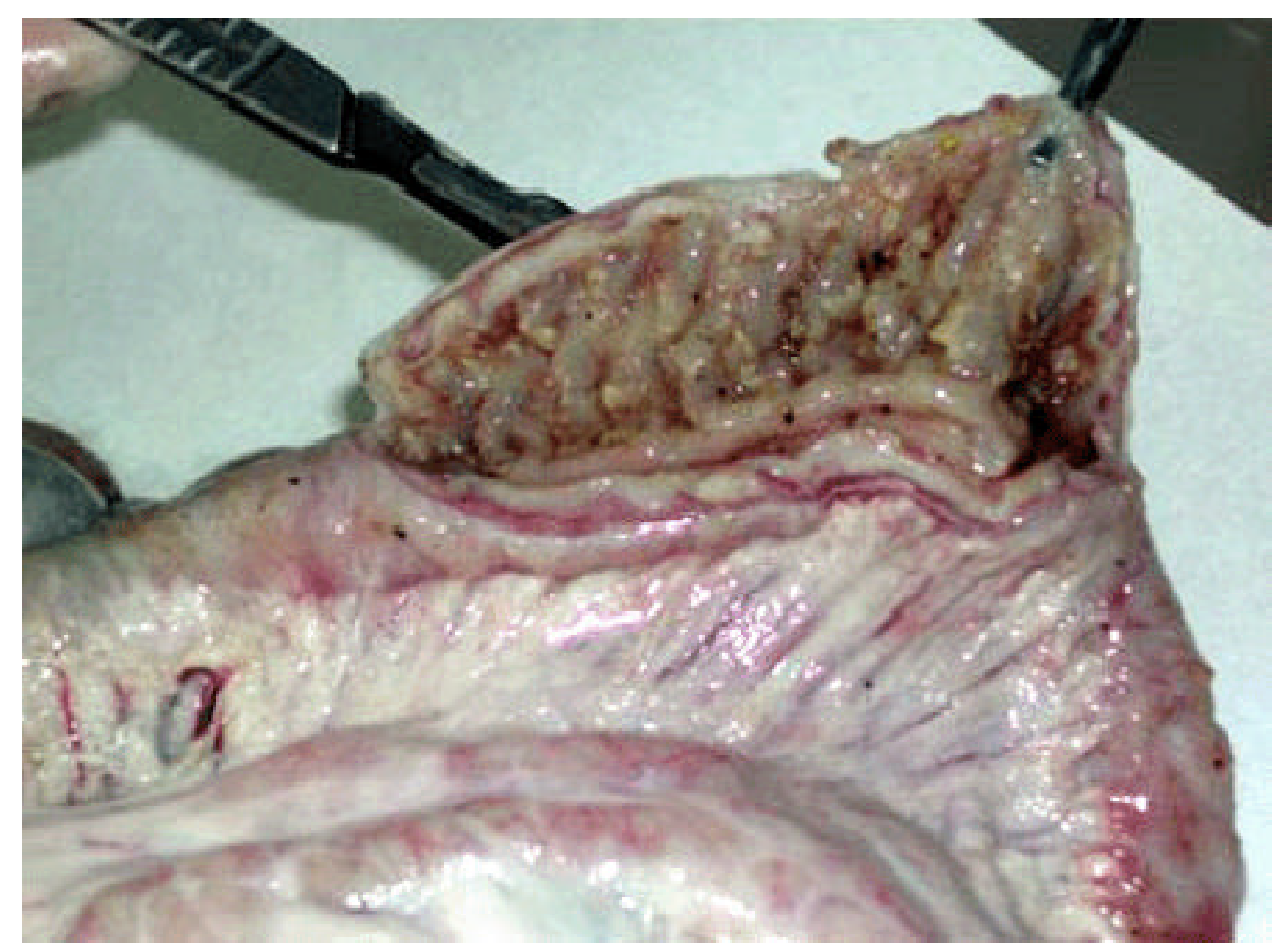

Figura 1. Enteropatía proliferativa

no hemorrágica y estreñimiento, que ocasionan una notable pérdida en la ganancia de peso. En las formas más graves los animales pueden morir súbitamente, apreciándose en la necropsia una fuerte enteritis de carácter hemorrágico; no obstante, el índice de mortalidad es bajo (Fig. 1).

Para el presente estudio, en marzo del 2001 se tomaron 197 muestras de sangre a cerdos aparentemente sanos de granjas porcinas tecnificadas localizadas en las zonas de Cieneguilla, Lurín y Huaral, en Lima, Perú. Los datos de los animales fueron distribuidos en tres grupos: destete, hembras de reemplazo y engorde $(37,69$ y 75 días de edad, respectivamente). En el cálculo del tamaño muestral se utilizó la fórmula de cuantificación con una prevalencia referencial del 15\% (Veenhuizen et al., 1998), con un $95 \%$ de confianza y un error máximo admisible del 0.05 .
Se usó la prueba de inmunofluorescencia indirecta (ILEI-Test) para el análisis de las muestras. El suero obtenido fue diluido con PBS en 1:30 (Lawson et al., 1988; Knittel, 1998). La muestra se consideró positiva a L. intracellularis cuando se evidenció la fluorescencia producida por la adhesión de anticuerpos presentes en el suero con el antígeno bacteriano presente en la lámina y a la adhesión del anti-anticuerpo de porcino conjugado con la fluoresceína. Al final del ensayo se colectaron tejidos de yeyuno, íleon $\mathrm{y}$ colon a los animales que presentaron un cuadro compatible con Lawsonia, para su análisis histopatológico.

El $38.7 \%$ de los sueros (73 muestras) resultaron positivos a la presencia de anticuerpos contra L. intracellularis. Sin embargo, al tomar en cuenta la sensibilidad y especificidad de la prueba, se obtuvo una prevalencia corregida de $37.1 \pm 6.8 \%$. El Cua- 


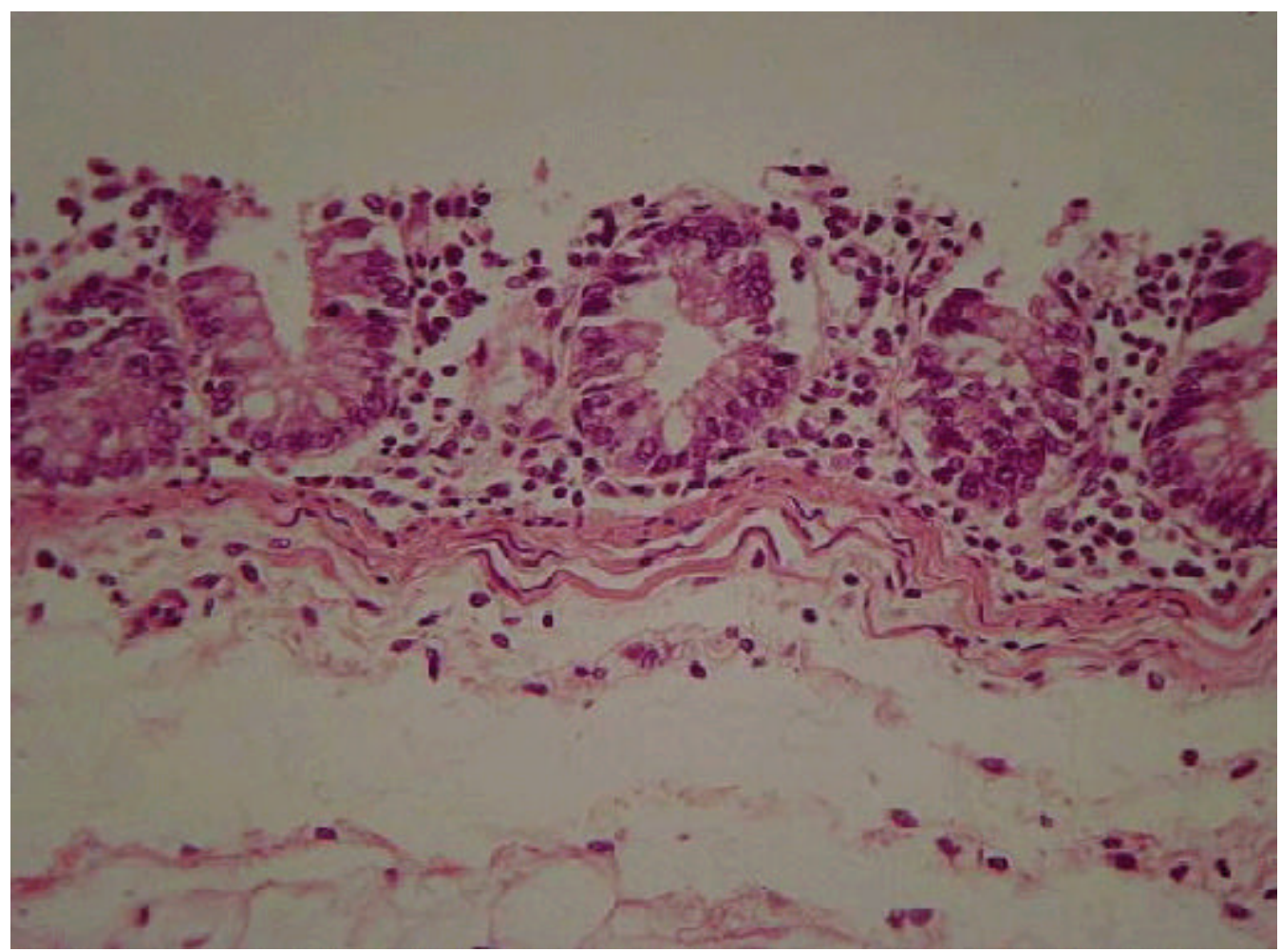

Figura 2. Corte histopatológico a nivel de íleon

Cuadro 1. Prevalencia de anticuerpos contra Lawsonia intracellularis en tres zonas de Lima-Perú

\begin{tabular}{lccc}
\hline Zona & Total de muestras & $\begin{array}{c}\text { Positivos } \\
\text { (n) }\end{array}$ & $\% \pm$ I.C. ${ }^{1}$ \\
\hline Huaral & 66 & 13 & $19.0 \pm 9.2$ \\
Cieneguilla & 69 & 29 & $44.3 \pm 11.7$ \\
Lurín & 72 & 31 & $45.5 \pm 11.5$ \\
Total & 197 & 73 & $38.7 \pm 6.8$ \\
\hline
\end{tabular}

${ }^{1}$ Prevalencia corregida según el porcentaje de sensibilidad de $91 \%$ y especificidad de $97 \%$

dro 1 presenta la distribución de porcinos positivos a la presencia de anticuerpos contra $L$. intracellularis, observándose menor porcentaje de animales reactores en la provincia de Huaral con respecto a Cieneguilla y Lurín. Trabajos realizados en otros países determinaron prevalencias similares a las encontradas en este trabajo (Smith y McOrist, 1997). Las condiciones de manejo y el tipo de ani- males en cada una de las zonas de estudio fueron similares, sospechándose que el menor factor de riesgo de presentación pudiera deberse al clima, donde Huaral presenta una temperatura más constante durante el día con relación a las otras dos zonas, ya que los cambios de temperatura son un factor que propicia formas de presentación más graves de la enfermedad (McOrist y Gebhart, 1996). 
Cuadro 2. Evaluación de la edad como factor de riesgo en la presentación de anticuerpos contra Lawsonia intracellularis obtenidas según grupo etario

\begin{tabular}{lccccc}
\hline Edad & Total de muestras & $\begin{array}{c}\text { Positivos } \\
\text { (n) }\end{array}$ & $\% \pm$ I.C. & Odds Ratio & IC \\
\hline Destete & 69 & 17 & $24.6 \pm 10.1$ & 0 & 0 \\
Engorde & 69 & 31 & $47.6 \pm 11.7$ & 1.78 & $0.94-3.33$ \\
Reemplazo & 59 & 25 & $44.7 \pm 12.7$ & 0.98 & $0.51-1.90$ \\
\hline Total & 197 & 73 & $38.7 \pm 6.8$ & & \\
\hline
\end{tabular}

${ }^{1}$ Prevalencia corregida según el porcentaje de sensibilidad de $91 \%$ y especificidad de $97 \%$, y el factor de riesgo

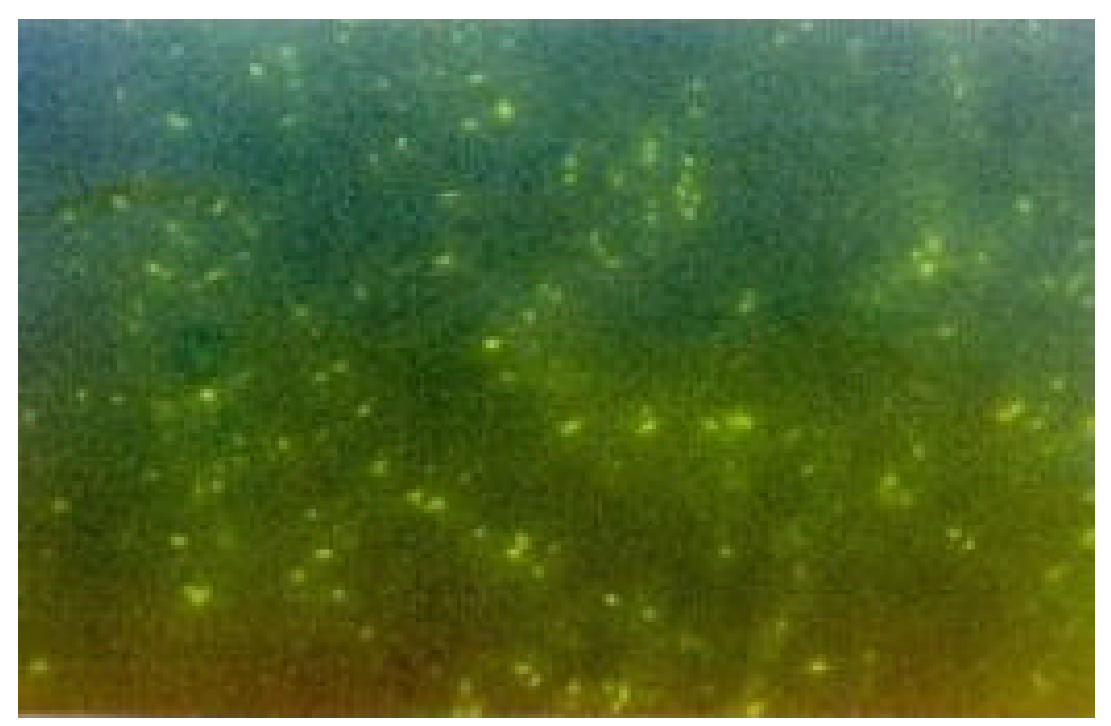

Figura 3. Técnica histoquímica utilizando la coloración de Warthin-Starry

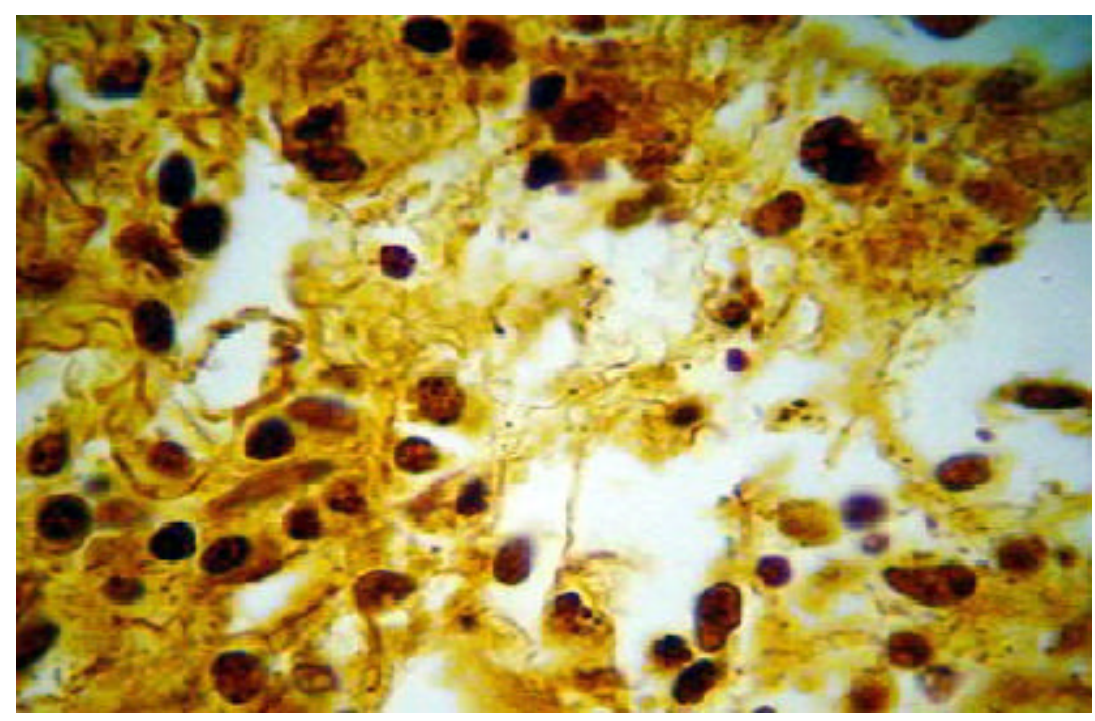

Figura 4. Inmunofluorescencia positiva (IF). Se observa la fluorescencia de Lawsonia intracellularis 
Se observa menor prevalencia en animales destetados y mayor porcentaje en animales de engorde (Cuadro 2), similar a los resultados encontrados en Venezuela y España (Hurtado et al., 1999; Lanza y Pozo, 1996). La presencia de animales destetados seropositivos podría deberse a la presencia de anticuerpos maternales, lo que a su vez indicaría una infección de la madre. Sin embargo, al evaluar el grupo etario como factor de riesgo no se demostró influencia alguna.

El 8\% de los animales presentaron cuadros de diarrea y pérdida de condición. Se sacrificaron cuatro animales observándose en la luz intestinal del íleon la presencia de masas gelatinoides rojizas con fluido; y en otros sectores, masas amarillentas adheridas a la mucosa, además de pseudomembranas mucosas y aparente leve engrosamiento de las capas musculares. En el análisis histopatológico se observó necrosis y atrofia de las vellosidades intestinales, dilatación y ramificación de las criptas con infiltración de neutrofilos en el lumen (Fig. 2). En otras secciones se observó en las vellosidades intestinales una leve proliferación de enterocitos inmaduros, escasas células caliciformes, epitelio descamado, severa necrosis de la glándula de Lieberkhün, infiltración de mononucleares en el corion, y hacia la luz, restos de células descamadas, depósito de fibrina y presencia de una flora mixta de microorganismos cocobacilares basófilos y espiralados; estos últimos positivos a la técnica de WarthinStarry (Fig. 3).

Los resultados indican la presencia de un cuadro lesional de severa ileítis fibrino supurativa hemorrágica difusa aguda bacteriana, compatible con una ileitis necrótica causada por L. intracellularis.

A la fecha, se desconoce como ingresó esta enfermedad al Perú o si ha existido por muchos años sin que haya sido correctamente identificada. Se sospecha que esta bacteria es ubicua de los cerdos y hay indicios de que existe una transmisión entre roedores y cerdos (Gebhart et al.,1993). Así mismo, las relaciones comerciales con los EE.UU. y los países europeos para la adquisición de cerdos puede haber sido una puerta de entrada, ya que en esos países se ha detectado la enfermedad con anterioridad.

Se puede concluir que los animales que resultaron seropositivos con la prueba IFI habrían tenido un desafio de campo con $L$. intracellularis, ya que obtuvo una seroprevalencia del $38.7 \%$, y donde el mayor porcentaje de animales afectados ocurrió en la etapa de engorde. Además, se observaron diversas lesiones macroscópicas ileales, y en los cortes histopatológicos de íleon se encontraron lesiones compatibles con ileitis necrótica producida por L. intracellularis.

\section{Literatura Citada}

1. Biester, H.E.; L.H. Schwarte. 1931. Intestinal adenoma in swine. Am. J. Pathol. 7: 175-185.

2. Chiriboga, A.E.; W.V. Guimaraes; M.C. Vanetti; E.F. Araujo. 1999. Detection of Lawsonia intracellularis in faeces of swine from the main producing regions in Brazil. Can. J. Microbiol. 45: 230-234.

3. Gebhart C.J.; S.M. Barn; S. McOrist. 1993. Ileal symbiotic intracellularis, and obligate intracellular bacterium of porcine intestines showing a relationship to Desulfovibrio species. Int. J. Syst. Bacteriol. 43: 533-538.

4. Hurtado, M.E.; R. Maerstro; M. Rolo; L. Palencia. 1999. Evaluaciones serológicas preliminares para detección de anticuerpos contra Lawsonia intracellularis en cerdos de granjas venezolanas. Rev. Porc. Venez. 21: 14-15.

5. Knittel, J.P. 1998. New serology test available. Am. J. Vet. Res 56: 722-726.

6. Lawson, G.H.K.; S. McOrist; A.C. Rowland; L. Roberts; E. McCartney. 1988. Serological diagnosis of the porcine proliferative enteropathies: 
implications for etiology and epidemiology. Vet. Rec. 122: 554-557.

7. Lanza, I.; J. Pozo. 1996. Epidemiología de la ileitis porcina. Porc. Vet. 32: 42-39.

8. McOrist, S.; C.J. Gebhat; R. Boid; S.M. Bars. 1995. Characterization of Lawsonia intracellularis gen. nov, sp. nov, the obligate intracellular bacterium of porcine proliferative enteropathy. Int. J. Syst. Bacteriol. 45: 820-825.

9. McOrist, S.; J. Morgan; M.F. Veenhuizen; K. Lawrence; H.W. Kroger. 1997. Oral administration of tylosin phosphate for treatment and prevention of proliferative enteropathy in pig. Am. J. Vet. Res. 58: 136-139.
10. Mc Orist, S.; C.J. Gebhart. 1996. Swine diseases. $6^{\text {h }}$ ed. p 521-533. Ed. Iowa State Univ. USA.

11. Pointon, A.M. 1989. Campylobacter associated intestinal pathology in pigs. Aust. Vet. J. 66: 90-91.

12. Smith, S.H.; S. McOrist. 1997. Development of persistent intestinal infection and excretion of Lawsonia intracellularis by piglets. Res. Vet. Sci. 62: 6-10.

13. Veenhuizen, M.F.; T.E. Elan; N. Soensken. 1998. The potential economic impact of porcine proliferative entheropathy on the use in swine industry. XV Congress IPVS 2: 64. 